Aroma analysis and data handling in the evaluation of niche apple juices from 160 local danish apple cultivars

Varming, Camilla; Amigo Rubio, Jose Manuel; Petersen, Mikael Agerlin; Toldam-Andersen, Torben Bo

Publication date:

2011

Document version

Early version, also known as pre-print

Citation for published version (APA):

Varming, C., Amigo Rubio, J. M., Petersen, M. A., \& Toldam-Andersen, T. B. (2011). Aroma analysis and data handling in the evaluation of niche apple juices from 160 local danish apple cultivars. 


\title{
AROMA ANALYSIS AND DATA HANDLING IN THE EVALUATION OF NICHE APPLE JUICES FROM 160 LOCAL DANISH APPLE CULTIVARS
}

\author{
CAMILLA VARMING ${ }^{1}$, JOSÉ MANUEL AMIGO ${ }^{1}$, MIKAEL AGERLIN PETERSEN ${ }^{1}$, TORBEN TOLDAM-ANDERSEN ${ }^{2}$ \\ ${ }^{1}$ Department of Food Science, ${ }^{2}$ Deptartment of Agriculture \& Ecology
} cva@life.ku.dk

\section{INTRODUCTION}

Apple juice has traditionally been a low cost product made from fruit not meeting the quality demands for fresh consumption due to factors like appearance, firmness or sensitivity to bruising. These criteria are however not critical in juice processing and some of the old local cultivars may have unique flavour qualities that can be attractive in juices.

In the present study, juices from 160 local apple cultivars were analysed. Analysing such large number of samples, with a great genetic variation can introduce challenges like baseline drifts, peak shift, co-elution and a tedious job manually desiccating all the chromatograms. In the present study advanced data analysis methods (PARAFAC2 and PCA) for GC-MS data evaluation were applied.

\section{EXPERIMENTAL ST}

MATERIALS

160 Danish apple cultivars were obtained from University of Copenhagen's experimental orchard ('Pometet') hosting the collection of national and international fruit genotypes. Juices were produced by a small hydropress and pasteurised.

AROMA ANALYSES

Aroma analyses of the juices was performed by dynamic headspace GC-MS.

CHROMATOGRAPHIC DATA TREATMENT MS fingerprint was used to elucidate patterns in the chromatograms, and Multi-way analysis (Parallel Factor Analysis 2, PARAFAC2 see below) was applied in 24 selected MS scan intervals areas to resolve areas with overlapped peaks.
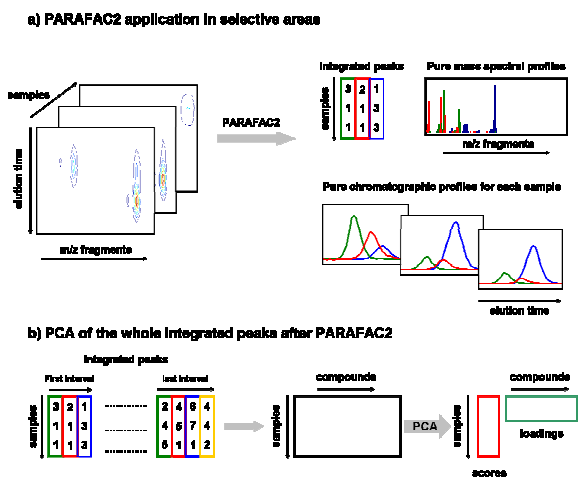

\section{RESULTS AND DISCUSSION}

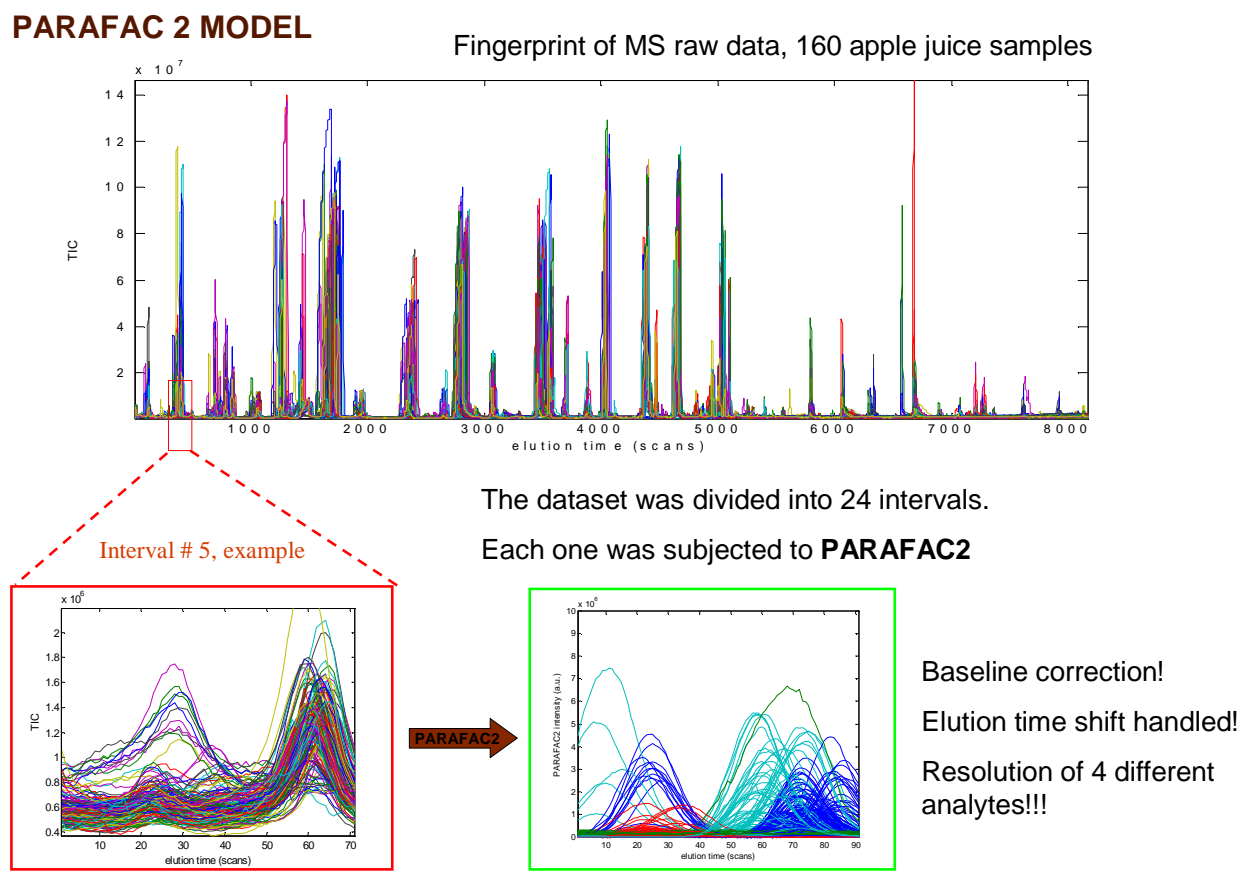

\section{PCA WITH PARAFAC2 RESULTS}

As the scores plot reveals, there are large differences in patterns between the juices of different apple cultivars. No clear classification/clustering occur and anyway very little is known about the genetics of these old local cultivars.

Some cultivars (score plot, positive PC1 side) possess very high levels of the aroma compounds represented by the scan intervals

Nearly all variables are located in the positive part of the PCA, hence a large number of cultivars are characterised by the absence of volatile compounds

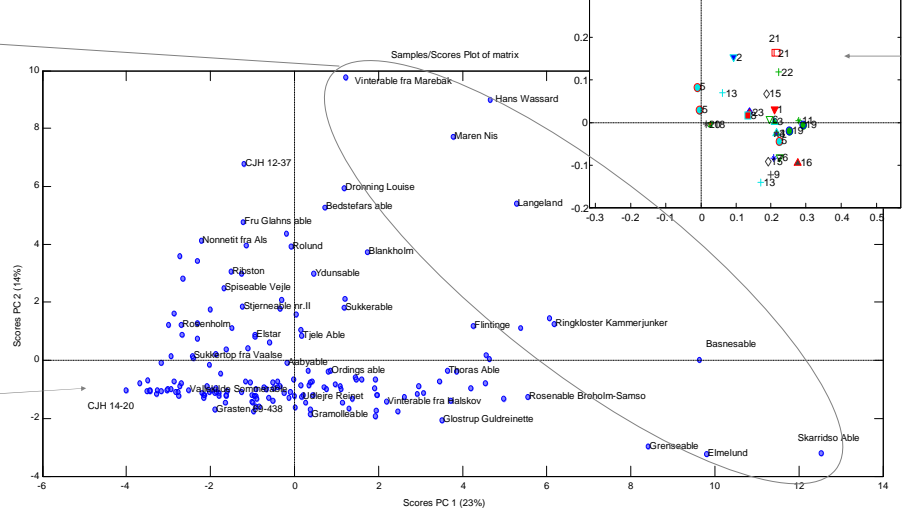

\section{CONCLUSION}

-Typical chromatographic problems have been solved!

\& FURTHER TASKS

-Identification of aroma compounds

-There are large differences in the volatile profiles of in the 24 MS intervals

The present study is part of the "YDUN" project aiming to promote the utilization of Danish apple cultivars and increase the competitiveness of growers in the market, by identifying the suitability of local cultivars for niche markets for fruit juices with tailored sensory and nutritional labels.

The final results will be integrated into the online "Apple PC-Key" (www.nordgen.org/nak/) database which is being developed to promote interest in the old Nordic apple cultivars and provide public access to the knowledge. 